(C) ACM, 2021. This is the author's version of the work. It is posted here by permission of ACM for your personal use. Not for redistribution. The definitive version was published in CHI EA '21: Extended Abstracts of the 2021 CHI Conference on Human Factors in Computing Systems, ISBN: 978-1-4503-8095-9,

https://doi.org/10.1145/3411763.3441320

\title{
EduCHI 2021
}

$3^{\text {rd }}$ Annual Symposium on $\mathrm{HCl}$ Education

CRAIG M. MACDONALD

Pratt Institute, USA

OLIVIER ST-CYR

University of Toronto, Canada

COLIN M. GRAY

Purdue University, USA

LEIGH ELLEN POTTER

Griffith University, Australia

JAISIE SIN

University of Toronto, Canada

ANNA VASILCHENKO

Newcastle University, UK

\section{ELIZABETH CHURCHILL}

Google Inc., USA

The HCI Education Community of Practice (CoP) has grown considerably over the past few years, starting with the HCI Living Curriculum workshop at CHI 2018 and continuing through to the EduCHI symposia at both CHI 2019 and CHI 2020. Central to the growth of the CoP has been two parallel efforts: creating channels to discuss issues pertinent to HCI education and providing a platform for sharing HCI curricula and teaching experiences. To continue this progress, we are organizing EduCHI 2021, the 3rd Annual Symposium on HCI Education. EduCHI 2021 will be held virtually and will feature interactive discussions about HCI education trends, curricula, pedagogies, teaching practices, and current and future challenges facing HCI educators.

CCS CONCEPTS • Social and professional topics $\sim$ Professional topics $\sim$ Computing education

Additional Keywords and Phrases: HCI education, HCI curriculum, Community of Practice ACM Reference Format:

First Author's Name, Initials, and Last Name, Second Author's Name, Initials, and Last Name, and Third Author's Name, Initials, and Last Name. 2018. The Title of the Paper: ACM Conference Proceedings Manuscript Submission Template: This is the subtitle of the paper, this document both explains and embodies the submission format for authors using Word. In Woodstock '18: ACM 
Symposium on Neural Gaze Detection, June 03-05, 2018, Woodstock, NY. ACM, New York, NY, USA, 10 pages. NOTE: This block will be automatically generated when manuscripts are processed after acceptance.

\section{BACKGROUND}

The past few years has seen rapid growth of an international Community of Practice (CoP) dedicated to HumanComputer Interaction (HCI) education. The root of these efforts began in 2011 when the ACM Special Interest Group on Computer-Human Interaction (SIGCHI) Executive Committee sponsored a project to investigate the present and future of HCI education [1], with the ultimate goal of updating the ACM SIGCHI Curricula for Human-Computer Interaction (published back in 1992) [6]. Throughout this project, a common request from HCI scholars and educators was the creation of a living curriculum, or an evolving online collection of course outlines, curricula, and teaching materials [2]. Subsequent efforts to build support and interest in this initiative included workshops at CHI 2014 [3] and AfriCHI 2016 [7], additional data collection at CHI 2017 [8,9], and, finally, a workshop at CHI 2018 [14] to launch the creation of a Community of Practice ( $\mathrm{CoP}$ ) dedicated to building excitement and interest in the living curriculum [11].

The HCI Education CoP has two parallel aims: (1) creating channels to discuss issues pertinent to HCI education and (2) providing a platform for sharing HCI curricula and teaching experiences. The EduCHI Symposia, held in conjunction with the $\mathrm{CHI}$ conference for the last two years, has played a vital role in growing and sustaining the HCI Education CoP by providing opportunities for educators to reflect on current and future HCI education trends and also offering a venue to share insights about successful HCI curricula, pedagogies, and teaching practices.

We must also acknowledge the vital role a CoP can play in helping educators navigate pressing issues and challenges: (1) the COVID-19 pandemic and its associated economic, public health, and mental health fallout; and (2) the struggle for racial justice and equality, sparked by the May 2020 death of George Floyd at the hands of a white police officer in Minnesota. In the former case, HCI educators are being asked to adopt new remote learning platforms and tools and keep students engaged and supported, while also maintaining their own mental and physical well-being. In the latter case, HCI educators are seeking ways to actively diversify and decolonize their courses and curricula to create inclusive, safe, and welcome spaces for all learners regardless of race, gender identity, religion, or culture. The HCI Education CoP held two virtual events in the summer 2020 to initiate conversations and discuss and share strategies around these topics. In these uncertain and difficult times, these discussion channels and platforms offer educators a valuable lifeline to a community of supportive and knowledgeable experts and peers.

Following up on these efforts, our goals for EduCHI 2021, the 3rd Annual Symposium on HCI Education, are as follows:

1. Continue growing the HCI education CoP;

2. Provide a platform for discussing current and emerging trends in HCI education;

3. Share innovative pedagogies and teaching methods by HCI educators to enhance broader teaching practice; and

4. Promote and support a global, diverse, and inclusive vision for HCI education. 


\section{ORGANIZERS}

The team below includes faculty and students who are active HCI educators and researchers and were all involved in organizing the EduCHI 2020 Symposium [15]. The first two authors and the last author were also the lead organizers of the CHI 2018 workshop on Developing a Community of Practice to Support Global HCI Education (W25) [13]] and the CHI 2019 EduCHI Symposium on Global Perspectives on HCI Education [12]. The other organizers are authors of previous HCI education research [4,5,10,16-18].

Craig M. MacDonald is an Associate Professor in the School of Information at Pratt Institute where he developed the Master of Science in Information Experience Design program and directs the Center for Digital Experiences. He holds a Ph.D. in Information Studies and Human-Computer Interaction from Drexel University and his research focuses on building organizational UX capacity in practical settings and strengthening HCI/UX education.

Olivier St-Cyr is an Assistant Professor, Teaching Stream in the Faculty of Information at the University of Toronto, in Toronto, Canada. He is the liaison for the iSchool User Experience Design (UXD) concentration. His research interests lie in the areas of HCI education and HCI curriculum development. Prior to joining the University of Toronto, he spent eight years working in industry on HCI related projects.

Colin M. Gray is an Assistant Professor at Purdue University, where he is program lead for an undergraduate major and graduate concentration in UX Design. His research focuses on the ways in which the pedagogy and practice of designers informs the development of design ability, particularly in relation to ethics, design knowledge, and professional identity formation. His work crosses multiple disciplines, including human-computer interaction, instructional design and technology, design theory and education, and engineering and technology education.

Leigh Ellen Potter is a senior lecturer and Director of the IDEA Lab at Griffith University, Australia. Through both her research and her industry work, Dr Potter has specialised in participatory design, user experience, usability analysis, and technology evaluation. Her current work explores the application of emerging technology in teaching situations, and the active involvement of students as design partners in the development process. She was awarded the Griffith Award for Excellence in Teaching (Innovation in Learning Design), and is a Fellow of the Griffith Learning and Teaching Academy.

Jaisie Sin is a graduate student at the Technologies for Aging Gracefully Lab and the Faculty of Information at the University of Toronto, in Toronto, Canada. There, she is a teaching assistant and course instructor for various courses in human-computer interaction, software development, and software design. She also holds a Master of Information in User Experience Design from the University of Toronto. Her research focuses on inclusive design from the sociotechnical perspective of the marginalization of underrepresented users like older adults through design.

Anna Vasilchenko is a researcher at Open Lab, Newcastle University, UK. Anna's research interests are centered around innovative methods of teaching and learning for STEM subjects in higher education, while specific focus of her PhD project was on HCI and Ubicomp education. For that, she investigated how student-generated content and blended learning, which are built around ideas of 'learning through making' and 'peer learning', could help to address some of the challenges in teaching such a multifaceted field as HCI.

Elizabeth F. Churchill is a Director of User Experience at Google focused on designer and developer tools for the connected ecosystems of the Social Web and Internet of Things. Elizabeth has been a research leader at wellknown corporate R\&D organizations including Fuji Xerox's research lab in Silicon Valley (FXPAL), the Palo Alto Research Center (PARC), eBay Research Labs in San Jose, and Yahoo! in Santa Clara, California. A Distinguished 
Scientist and Speaker of the Association for Computing Machinery (ACM) and a member of the CHI Academy, Elizabeth most recently served as ACM Secretary/Treasurer and is the current ACM Vice President.

\section{WEBSITE}

The symposium website is available at https://educhi2021.hcilivingcurriculum.org/. The website contains background information about HCI education and our motivations for holding the symposium, details about the symposium organizers, and the call for participation. It will also contain the symposium agenda and downloadable copies of all accepted papers.

\section{PRE-SYMPOSIUM PLANS}

We will distribute a call for participation to all attendees from our CHI 2018 workshop and both the CHI 2019 and CHI 2020 symposia. Moreover, we will distribute the call on relevant academic mailing lists, including the recently re-launched CHI-EDUCATION listserv, and through social media, specifically through the HCI Education Facebook group (402 members, as of 14 October) and the @HCI_Education Twitter account (274 followers, as of 14 October). We will also actively solicit submissions from individuals who have expressed an interest in HCI education issues, either through their involvement in previous HCI education activities or through published research about education-related topics. Our goal is to solicit submissions from a broad and diverse range of HCI and humancentered educators, recruited from all regions of the world (e.g., Africa, Asia, Europe, North America, etc.), from different disciplinary perspectives (e.g., design, computer science, CSCW, information science, psychology, etc.), institutional perspectives (public, private, graduate, undergraduate, and historically black colleges and universities and other similar institutions), and with a variety of cultural viewpoints. EduCHI 2020 received 29 submissions, of which 14 were accepted (48\%). This year, we again aim to receive 25 to 30 submissions, of which we plan to accept approximately 12-14 to be presented or discussed at the symposium. We will promote the completed program through the same venues as above, and through that we hope to recruit an additional 25 to 40 attendees.

Potential presenters will be asked to submit a 4-10-page paper in the new single-column ACM Master Article Submission template. All aspects and topics related to HCI education will be welcomed, including, but not limited to: research related to HCI education, effective HCI pedagogies and teaching practices (e.g., assignments/assessments, labs, studios, active learning activities, resources, readings, case study, lecture materials, online/remote teaching, diversification of HCI curricula, etc.), presentations of HCI curricula and their deployment, thought-provoking or inspirational perspectives on HCI education, and descriptions of unsolved HCI education challenges. Papers and participants will be selected based on their experience, perspective, and potential to engage symposium attendees in thoughtful discussions.

Following a successful acceptance, participants will be asked to prepare the final camera-ready version of their submission which will be posted on the symposium website prior to the event. Participants will also be given the option of creating a pre-recorded presentation and other supplemental content about their submission (slides, video, etc.) to be published on the symposium website and distributed to attendees prior to the event.

\section{SYMPOSIUM STRUCTURE}

Our symposium will be a four-hour virtual event in which participants will be an integral part in presenting their vision and perspectives on HCI education. The symposium will be conducted entirely via Zoom (or a similar video 
conferencing platform) and will also utilize a shared Google document to facilitate discussion. To maximize engagement and encourage both formal and informal knowledge sharing, the symposium will feature a mix of prerecorded and live presentations followed by interactive discussion sessions. To build the technical program, we will be soliciting four distinct types of paper submissions:

- Research Papers: describe novel research on or about HCI education, following a traditional research paper format.

- Provocations: present a new, controversial, inspiring, or otherwise thought-provoking perspective on or about HCI education.

- Teachable Moments: describe and/or demonstrate an interesting or innovative teaching method, curricular approach, or other pedagogical tools for HCI educators.

- Unsolved Challenges: outline an unsolved problem, issue, or challenge faced by HCI educators and solicit a request for solutions that may address it.

At the beginning of the symposium, we will briefly discuss its background and goals. The main program will then be split into three sessions of roughly 60-90 minutes each, with each session featuring a combination of short informal presentations (research papers and provocations), brief interactive demonstrations (teachable moments), and open discussions (unsolved challenges). The symposium will conclude with a short brainstorming session led by the organizers about the future of the HCI Education Community of Practice. After the symposium, we will invite participants to a Happy Hour session in Social VR space where they will be able to informally meet their old and new friends and/or continue discussions started earlier at the symposium

Below is the proposed symposium schedule; the exact times may be modified to accommodate symposium attendees who live in different time zones:

10:00 - 10:10 Welcome, agenda, background, and goals

10:10 - 10:30 Paper Session I: paper presentations + demonstrations

10:30 - 11:15 Discussion Session I: unsolved challenge discussion

11:15 - 11:25 Break

11:25 - 11:45 Paper Session II: paper presentations + demonstrations

11:45 - 12:30 Discussion Session II: Unsolved challenge discussion

12:30 - 12:40 Break

12:40 - 13:00 Paper Session III: paper presentations + demonstrations

13:00 - 13:45 Discussion Session III: unsolved challenge discussion

13:45 - 14:00 Closing: the future of HCI education CoP

AFTER: Social VR Happy Hour

Live captioning will be provided through Microsoft PowerPoint's live captioning feature. This is a method used in previous virtual workshops and conferences with favorable results. If possible, we will supplement this with a recruited live captioner.

\section{POST-SYMPOSIUM PLANS}

All papers and presentations will be archived on the symposium website. Moreover, we will post a link to the Google doc created during the symposium, which will capture notes and resources shared by attendees during the event. We will also keep the HCI education community aware of developments through our Facebook HCI Education group 
and our twitter account (@HCI_Education). Further, we will continue organizing virtual meetings on issues discussed at the symposium and other topics of interest to the HCI education community.

\section{CALL FOR PARTICIPATION}

EduCHI 2021, the 3rd Annual Symposium on HCI Education, will bring together an international community of scholars, practitioners, and researchers to shape the future of HCI education. Held virtually as part of the CHI 2021 conference, EduCHI 2021 will feature interactive discussions about HCI education trends and challenges and provide a platform for sharing HCI curricula, materials, and teaching experiences.

To participate, we are seeking four types of submissions:

1. Research: Describe novel research on or about HCI education, following a traditional research paper format.

2. Provocations: Present a new, controversial, inspiring, or otherwise thought-provoking perspective about HCI education.

3. Teachable Moments: Describe or demonstrate an interesting or innovative teaching method, curricular approach, or other pedagogical tool for HCI educators.

4. Unsolved Challenges: Explain an unsolved HCI education problem or other concern for HCI educators. A selection of these challenges will be discussed during the symposium.

To apply, authors should prepare a 4-10-page paper using the new ACM Master Article Submission template and submit it via educhi2021.hotcrp.com by 12 February 2021.

Applicants will be selected based on their experience, perspective, and potential to engage attendees in thoughtful discussions. Following a successful acceptance, authors will be asked to prepare a final camera-ready version of their paper and given the option of creating a pre-recorded presentation that will be shared prior to the symposium. All accepted papers and supplemental materials will be posted on the symposium website at educhi2021.hcilivingcurriculum.org. At least one author of each accepted paper must register for the symposium.

\section{REFERENCES}

[1] Elizabeth F. Churchill, Anne Bowser, and Jennifer Preece. 2013. Teaching and learning human-computer interaction. interactions 20, 2 (March 2013), 44. DOI:https://doi.org/10.1145/2427076.2427086

[2] Elizabeth F. Churchill, Anne Bowser, and Jennifer Preece. 2016. The Future of HCI Education: A Flexible, Global, Living Curriculum. Interactions 23, 70-73. DOI:https://doi.org/10.1145/2888574

[3] Elizabeth Churchill, Jennifer Preece, and Anne Bowser. 2014. Developing a living HCI curriculum to support a global community. In Proceedings of the extended abstracts of the 32nd annual ACM conference on Human factors in computing systems - CHI EA '14, ACM Press, New York, New York, USA, 135-138. DOI:https://doi.org/10.1145/2559206.2559236

[4] Colin M Gray. 2014. Evolution of design competence in UX practice. In Proceedings of the 32nd annual ACM conference on Human factors in computing systems - CHI '14, ACM Press, New York, New York, USA, 1645-1654. DOI:https://doi.org/10.1145/2556288.2557264

[5] Colin M. Gray, Paul Parsons, and Austin L. Toombs. 2020. Building a Holistic Design Identity Through Integrated Studio Education. In Educational Technology Beyond Content. Educational Communications and Technology: Issues and Innovations, Brad Hokanson, Gregory Clinton, Andrew Tawfik, Amy Grincewicz and Matthew Schmidt (eds.). Springer, Cham, 43-55. D0I:https://doi.org/10.1007/978-3-03037254-5_4

[6] Thomas Hewett, Ronald Baecker, Stuart Card, Tom Carey, Jean Gasen, Marilyn Mantei, Gary Perlman, Gary Strong, and William Verplank. 1992. ACM SIGCHI Curricula for Human-Computer Interaction. ACM, New York. DOI:https://doi.org/10.1145/2594128

[7] Zayira Jordan, Jose Abdelnour Nocera, Anicia Peters, Susan Dray, and Stephen Kimani. 2016. A Living HCI Curriculum. In Proceedings of the First African Conference on Human Computer Interaction - AfriCHI'16, ACM Press, New York, New York, USA, $229-232$. DOI:https://doi.org/10.1145/2998581.2998623

[8] Andrea Jovanovic. 2018. Designing the HCI Living Curriculum. University of Toronto. Retrieved October 13, 2020 from http://hdl.handle.net/1807/89490

[9] Andrea Jovanovic, Olivier St-Cyr, and Mark Chignell. 2017. Towards the HCI Living Curriculum. In Proceedings of the Canadian Engineering 
Education Association (CEEA), Queen's University Library, Toronto, ON, Canada. DOI:https://doi.org/10.24908/pceea.v0i0.10383

[10] Leigh Ellen Potter. 2018. A Day in the Life. In Proceedings of the 2018 ACM SIGMIS Conference on Computers and People Research, ACM, New York, NY, USA, 138-142. DOI:https://doi.org/10.1145/3209626.3209716

[11] Olivier St-Cyr, Andrea Jovanovic, Mark Chignell, Craig M. MacDonald, and Elizabeth F. Churchill. 2018. The HCI living curriculum as a community of practice. Interactions 25, 5 (August 2018), 68-71. DOI:https://doi.org/10.1145/3215842

[12] Olivier St-Cyr, Craig M. MacDonald, and Elizabeth F. Churchill. 2019. EduCHI 2019 Symposium. In Extended Abstracts of the 2019 CHI Conference on Human Factors in Computing Systems, ACM, New York, NY, USA, 1-7. DOI:https://doi.org/10.1145/3290607.3298994

[13] Olivier St-Cyr, Craig M. MacDonald, Elizabeth F. Churchill, Jenny J. Preece, and Anna Bowser. 2018. Developing a Community of Practice to Support Global HCI Education. In Extended Abstracts of the 2018 CHI Conference on Human Factors in Computing Systems - CHI '18, ACM Press, New York, New York, USA, 1-7. DOI:https://doi.org/10.1145/3170427.3170616

[14] Olivier St-Cyr, Craig M. MacDonald, Elizabeth F. Churchill, Jenny J. Preece, and Anna Bowser. 2018. Developing a Community of Practice to Support Global HCI Education. In Extended Abstracts of the 2018 CHI Conference on Human Factors in Computing Systems, ACM, New York, NY, USA, 1-7. DOI:https://doi.org/10.1145/3170427.3170616

[15] Olivier St-Cyr, Craig M. MacDonald, Colin M. Gray, Leigh Ellen Potter, Anna Vasilchenko, Jaisie Sin, and Elizabeth F. Churchill. 2020. EduCHI 2020: 2nd Annual Symposium on HCI Education. In Extended Abstracts of the 2020 CHI Conference on Human Factors in Computing Systems, ACM, New York, NY, USA, 1-8. DOI:https://doi.org/10.1145/3334480.3375066

[16] Anna Vasilchenko, Adriana Wilde, Stephen Snow, Madeline Balaam, and Marie Devlin. 2018. Video coursework. In Proceedings of the 2018 International Conference on Advanced Visual Interfaces, ACM, New York, NY, USA, 1-3. DOI:https://doi.org/10.1145/3206505.3206596

[17] Mihaela Vorvoreanu, Colin M. Gray, Paul Parsons, and Nancy Rasche. 2017. Advancing UX education: A model for integrated studio pedagogy. In Conference on Human Factors in Computing Systems - Proceedings. DOI:https://doi.org/10.1145/3025453.3025726

[18] Adriana Wilde, Anna Vasilchenko, and Alan Dix. 2018. HCI and the educational technology revolution \#HCIEd2018. In Proceedings of the Workshop on Advanced Visual Interfaces AVI, ACM, New York, NY, USA, 1-3. DOI:https://doi.org/10.1145/3206505.3206600 